\title{
Risk of bias judgements and strength of conclusions in meta-evidence from the Cochrane Colorectal Cancer Group
}

\author{
John Delaney ${ }^{1,2^{*}}\left(\mathbb{D}\right.$, Rebecca Cui ${ }^{2}$ and Alexander Engel ${ }^{1,3}$
}

\begin{abstract}
Background: The Cochrane Collaboration records risk of bias (ROB) judgements on the original studies it analyses. The aim of this review is to perform an audit of all literature produced by the Cochrane Colorectal Cancer Group (CCCG), focusing on whether intervention type has any relationship with ROB and the ability of a review to inform clinical practice.
\end{abstract}

Methods: The most recent version of every CCCG review from January 2000 to the end of July 2018 was included. Conclusions were categorized as informing clinical practice (I) or not (N). Both I and N categories were divided into firm (F) or tempered (T) based on the definitiveness of their language. ROB judgements were aggregated. Reviews were classed as Medical (M), Surgical (S), Medical \& Surgical (MS) or Other (O) based on their intervention, with $O$ reviews then excluded. Data were analyzed in SPSS.

Results: Ninety-five reviews were included, covering 1892 studies. Sixty-two percent ( $n=59 / 95)$ informed clinical practice (I). Thirty-eight percent $(n=36 / 95)$ did not inform clinical practice $(\mathrm{N})$. Of the $\mathrm{N}$ group, $53 \%(n=19 / 36)$ were completely equivocal (firm) while $47 \%(n=17 / 36)$ were moderately so (tempered). In the I group, $46 \%$ $(n=27 / 59)$ gave a conclusion that was firm and $54 \%(n=32 / 59)$ were tempered. Seven thousand five hundred sixtyfour cases of bias were assessed. Risk of bias was low in 43\%, high in $20 \%$ and unclear in $37 \%$. A review that regarded a medical intervention alone was significantly more likely to be comprised of studies with a low risk of bias than a review that included a surgical intervention $(p<0.001)$.

Conclusion: The Cochrane Colorectal Cancer Group finds the risk of bias to be low in less than half of its judgements. A review that included a surgical intervention was less likely to display low risk of bias. Risk of bias was associated with whether a review informed clinical practice, but intervention type was not. Readers of colorectal literature should be cautious when considering original and meta-evidence in this field, particularly where a surgical intervention is assessed.

Keywords: Meta-analysis, Systematic review, Cochrane, Risk of bias, Epidemiologic methods

\section{Background}

The Cochrane Collaboration is an independent [1] global medical research organization [2], well regarded as having a high standard of methodology and rigor [3]. As part of their assessment of original evidence for inclusion in reviews, the Cochrane Collaboration typically assess each study's risk of bias (ROB), recording a judgement of "low risk", "high risk" or "unclear risk" across seven standard

\footnotetext{
* Correspondence: jdel2642@uni.sydney.edu.au

${ }^{1}$ Northern Clinical School, Sydney Medical School, University of Sydney, Sydney, Australia

${ }^{2}$ Royal Prince Alfred Hospital, Sydney, Australia

Full list of author information is available at the end of the article
}

criteria [4]. The criteria, familiar to many readers, were based on consensus expert review [5] and are intended to focus on the internal validity of studies. Assessment of ROB using the Cochrane tool has been previously noted to have high inter-rater variability [6], and the impact on effect size that a judgement of high or unclear bias in a particular domain has may vary according to the intervention and design of an original study [5]. A judgement of "unclear" may reflect a deficiency in the quality of reporting, rather than poor internal validity of the study. However, Cochrane's approach is regarded as the gold standard for risk of bias assessment in meta-evidence [7].

(c) The Author(s). 2019 Open Access This article is distributed under the terms of the Creative Commons Attribution 4.0 International License (http://creativecommons.org/licenses/by/4.0/), which permits unrestricted use, distribution, and 
Judgements of high or unclear risk have been associated with an over-appreciation of effect size [6]. The domains are listed in Table 1. Risk of bias judgements are collated and published in the finished reviews. Cochrane reviews are usually based on randomized control trials and do not consider "real-world data".

Cochrane's colorectal cancer group is the CCCG, the Cochrane Colorectal Cancer Group [8]. Each review published by the CCCG typically includes a recording of the ROB judgements of the relevant group of original studies. The overall picture of bias within the literature assessed by the CCCG has yet to be aggregated. This paper will collect and analyze all ROB judgements published by the CCCG, giving an overview of the risk of bias found in colorectal original research. The combined data will provide a view of the quality of a sample of colorectal literature over time, and a snapshot of its current status. It will also offer insight into the level of clinical utility of scientific publications within the colorectal domain; that is, when Cochrane reviews the colorectal literature, how often is it able to inform clinical practice?

As a subset of surgical intervention, laparoscopic surgery presents an example of the surgical research dilemma; technology precedes evidence, and the barriers to surgeons using new devices are low [9]. The learning curve of a new surgical implement and the pre-existing challenges of surgical research make robust conclusions about best practice difficult, particularly in the early phase of implementation [10]. This is in a commercial setting of high public demand and great marketing potential for new surgical technologies, as may also be seen currently with the popularity of robotic surgery $[11,12]$. Laparoscopic surgery ("key-hole" surgery) became widespread prior to significant evidence demonstrating its superiority over open approaches [13] and even now there remain some areas of controversy [14]. Subgroup analysis on laparoscopic papers from within the CCCG output was planned for this review as a means of assessing the meta-evidence support for this surgical technique.

\section{Methods}

\section{Literature search}

In collaboration with the CCCG, a list of all of that group's reviews from January 2000 to the end of July 2018 was acquired. The recorded ROB judgements for each study were also provided. The provided database was compared by two independent reviewers (JD and $\mathrm{RC}$ ) with reviews retrieved from the Cochrane Library to check accuracy.

\section{Definitions}

Risk of bias judgements are defined in the Cochrane Collaboration handbook [4]. Conclusion type was classified as "informs clinical practice-firm" (I-F), "informs clinical practice-tempered" (I-T), "does not inform clinical practice-tempered" (N-T) and "does not inform clinical practice-firm" (N-F). The definitions for these categories are outlined in Table 2 and have been described and used previously [15].

Reviews were classed as Medical (M), Surgical (S), Medical \& Surgical (MS) or Other (O) based on the intervention. An M paper considered an intervention that was exclusively medical, whereas an $\mathrm{S}$ paper examined an intervention that was exclusively surgical in nature. An MS paper was one where a surgical intervention was assessed in the setting of medical intervention or vice versa, for example, Epidural local anesthetics versus opioid-based analgesic regimens for postoperative gastrointestinal paralysis, vomiting and pain after abdominal surgery [16]. A review that did not assess an intervention or incorporated a therapy that was neither surgical nor medical (for instance, radiotherapy) was classified as "Other" $(\mathrm{O})$.

\section{Inclusion and exclusion criteria}

Included papers were systematic reviews and meta-analyses produced by the Cochrane Colorectal Cancer Group from January 2000 to the end of July 2018 that were classified as $\mathrm{M}, \mathrm{MS}$ or $\mathrm{S}$. Where more than one version of a review had been produced, the most up-to-date version was preferred. Reviews that were classified as $\mathrm{O}$ (that is, reviews that considered no intervention, or an intervention that was neither

Table 1 The Cochrane risk of bias tool

\begin{tabular}{ll}
\hline Risk of bias domain & Judgement \\
\hline Random sequence generation & $\begin{array}{l}\text { Selection bias (biased allocation to interventions) due to inadequate generation of a randomized sequence. } \\
\text { Selection bias (biased allocation to interventions) due to inadequate concealment of allocations prior to } \\
\text { assignment. }\end{array}$ \\
$\begin{array}{ll}\text { Blinding of participants and personnel } \\
\text { Blinding of outcome assessment } \\
\text { the study. }\end{array}$ \\
$\begin{array}{ll}\text { Incomplete outcome data } \\
\text { Selective reporting }\end{array}$ & $\begin{array}{l}\text { Attrition bias due to amount, nature or handling of incomplete outcome data. } \\
\text { Other bias }\end{array}$ \\
\hline
\end{tabular}


Table 2 Categories of conclusion type

\begin{tabular}{|c|c|}
\hline Conclusion type & Criteria \\
\hline Informs clinical practice-firm & $\begin{array}{l}\text { A conclusion that makes a recommendation for practice (positive or negative), with minimal or } \\
\text { no caveats. }\end{array}$ \\
\hline Informs clinical practice-tempered & $\begin{array}{l}\text { A conclusion that makes a recommendation for practice, but places significant caveats on that } \\
\text { recommendation. }\end{array}$ \\
\hline Does not inform clinical practice-tempered & $\begin{array}{l}\text { A conclusion that is unable to make a recommendation but suggests that a recommendation } \\
\text { might be possible soon based on an emerging trend or underlying theory. }\end{array}$ \\
\hline Does not inform clinical practice_-firm & $\begin{array}{l}\text { A conclusion that is unable to make a recommendation and is completely uncertain. There may } \\
\text { be no evidence at all, or of too poor a quality, or the evidence may be contradictory. }\end{array}$ \\
\hline
\end{tabular}

surgical nor medical) were a priori excluded from this analysis to facilitate comparison of surgical and medical interventions.

\section{Data extraction}

ROB judgements were extracted from each included Cochrane review. Conclusions and intervention type (M, S, MS or O) were scored independently by JD and RC. Each CCCG review was categorized based on its ability to inform clinical practice, using a standardized matrix (Table 2). Any disagreements were resolved by discussion to arrive at a consensus. Collation of data was performed in Microsoft Excel [17].

A subgroup of reviews concerning laparoscopic interventions was isolated and assessed (17 reviews). For visual comparison, a graphical representation of the commentary made on evidence within the conclusions of those reviews (a "word cloud") was generated using Microsoft Word.

\section{Statistical analysis}

Analysis of data was performed using SPSS v24 [18]. Inter-observer agreement was assessed using weighted kappa ( $\kappa$ ) [19]. Data that were categorical were analyzed was via cross tabulation with chi-square. A two-tailed distribution with an alpha level of 0.05 was used, with a Bonferroni correction where required. The means of continuous data were compared using one-way ANOVA with planned contrasts. An alpha level of 0.05 was used, again with a Bonferroni correction where required.

\section{Results}

The data provided by the CCCG included 117 unique Cochrane reviews. Twenty-two reviews were excluded from our audit; 9 regarded diagnostics rather than intervention, 5 reviews concerned radiotherapy, 4 examined herbal therapy, 3 regarded dietary modifications and 1 considered the impact of a perioperative blood transfusion (see Appendix 1 and 2). A PRISMA flow diagram may be found in Fig. 1. The PRISMA checklist is available as an Additional file 1. The 95 included reviews covered 1892 original studies. This created 13,244 possible cases of bias to be judged (7 bias categories across 1892 studies).
The CCCG made a combined total of 7564 judgements across the seven ROB categories. In 5680 instances, a ROB judgement was not recorded by the Cochrane Group (for example, when a review provided a judgement for some but not all of the ROB criteria). Overall, bias was judged as low $43 \%$ of the time $(n=$ $3291)$, high $20 \%$ of the time $(n=1490)$ and unclear $37 \%$ of the time $(n=2783)$. Bias judgements for each intervention type may be found in Table 3 . A chi-square test was performed, and a significant relationship found between the intervention type and the likelihood of a study to show differing bias (chi-square, $d f 4,41.696, p<$ 0.001). Comparison of individual groups using chi-square with a Bonferroni correction $(\alpha=0.0024)$ revealed $M$ to be more likely than $S$ and MS to have studies with a low risk of bias $(\mathrm{M}=50 \%>\mathrm{S}=42 \%, p<0.001)$, $(\mathrm{M}=50 \%>\mathrm{MS}=42 \%, \quad p=0.002)$. No difference was found in the likelihood of a low risk of bias when comparing $\mathrm{S}$ with MS $(p=0.831)$. Figure 2 displays low-risk judgements by intervention as a percentage of judgements made across Cochrane's seven categories. Assessment of the likelihood of high-risk judgements showed $S$ reviews to be more likely than $M$ reviews to show a high risk of bias $(\mathrm{S}=21 \% \mathrm{v} \mathrm{M}=16 \%, p<0.001)$. MS reviews were also more likely than $\mathrm{M}$ to display high risk (MS = $20 \%>M=16 \%, p<0.001)$. There was no difference in the likelihood of a high risk of bias between $\mathrm{S}$ and MS reviews $(p=0.2294)$.

$M$ had the greatest percentage of low-risk judgements across all risk-of-bias categories with the exception of selective reporting, where MS had the greatest percentage. When comparing $\mathrm{M}$ with $\mathrm{S}$ using chi-square with a Bonferroni correction $(\alpha=0.0024)$, M group reviews were found to be significantly more likely to be comprised of studies with a low risk of bias than $\mathrm{S}$ reviews in the category of blinding of participants and personnel $(\mathrm{M}=$ $35 \%>\mathrm{S}=21 \%, p<0.001)$. No difference was found in the likelihood to display low risk in random sequence generation $(\mathrm{M}=50 \%, \mathrm{~S}=42 \%, p=0.049)$, allocation concealment $(\mathrm{M}=44 \%, \mathrm{~S}=37 \%, p=0.035)$, blinding of outcome assessment $(\mathrm{M}=32 \%, \mathrm{~S}=22 \% p=0.007)$, incomplete outcome data $(\mathrm{M}=71 \%, \mathrm{~S}=67 \%, p=0.439)$, selective reporting $(\mathrm{M}=64 \%, \mathrm{~S}=54 \%, p=0.0145)$ and other bias $(\mathrm{M}=$ 


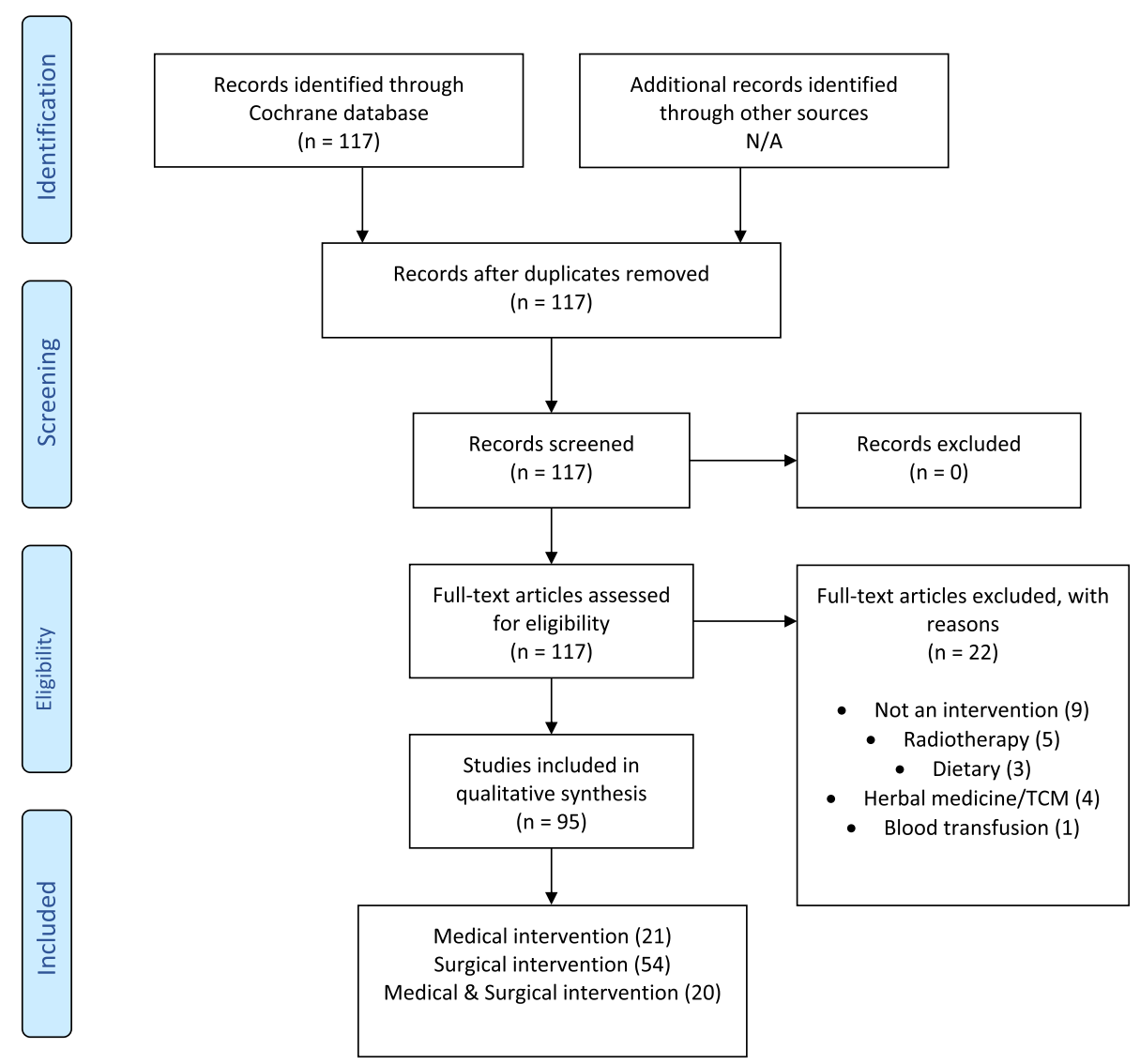

Fig. 1 PRISMA flow diagram

$59 \%, \mathrm{M}=51 \%, p=0.035)$. S reviews were more likely to display a high risk of bias than $\mathrm{M}$ reviews in the domains of random sequence generation $(\mathrm{S}=12 \%>\mathrm{M}=$ $2 \%, p<0.001)$ and $\mathrm{AC}(\mathrm{S}=11 \%>\mathrm{M}=2 \%, p<0.001)$. No difference was found in the chance of a high-risk judgement in the areas of blinding of participants and personnel ( $\mathrm{S}=41 \%, \mathrm{M}=44 \%, p=0.559)$, blinding of outcome assessment ( $\mathrm{S}=48 \%, \mathrm{M}=45 \%, p=0.616)$, incomplete outcome data $(\mathrm{S}=17 \%, \mathrm{M}=8 \%, p=0.005)$, selective reporting $(\mathrm{S}=13 \%, \mathrm{M}=7 \%, p=0.013)$ and other bias $(\mathrm{S}=16 \%, \mathrm{M}=15 \%, p=0.659)$.

Comparing $\mathrm{M}$ with MS, $\mathrm{M}$ reviews were significantly more likely to be comprised of studies displaying low bias in random sequence generation ( $\mathrm{M}=50 \%>\mathrm{MS}=36 \%, p<0.001)$, allocation concealment $(\mathrm{M}=44 \%>\mathrm{MS}=29 \%, p<0.001)$ and blinding of participants and personnel $(\mathrm{M}=32 \%>\mathrm{MS}=$ $19 \%, p<0.001)$. MS was more likely than $\mathrm{M}$ to display low bias in the domain of selective reporting ( $M S=88 \%>M=$ $64 \%, p<0.001$ ). Differences were not found between MS and $\mathrm{M}$ groups in the chance of a low-risk judgement in blinding of outcome assessment ( $\mathrm{M}=32 \%$, MS $=29 \%, p=0.534)$, incomplete outcome data $(\mathrm{M}=71 \%, \mathrm{MS}=68 \%, p=0.562)$ and other $(\mathrm{M}=59 \%, \mathrm{MS}=52 \%, p=0.173)$. MS reviews were more likely to have a judgement of high risk in the areas of allocation concealment (MS $=20 \%>M=2 \%, p<0.001)$ and incomplete outcome data ( $\mathrm{MS}=27 \%>\mathrm{M}=8 \%, p<0.001$ ). $\mathrm{M}$ was more likely to show high risk in blinding of participants and personnel $(\mathrm{M}=44 \%>\mathrm{MS}=24 \%, p<0.001)$. No difference in high-risk judgements were found in the areas of random sequence generation $(\mathrm{M}=2 \%, \mathrm{MS}=1 \%, p=0.764)$, blinding of outcome assessment $(\mathrm{M}=45 \%, \mathrm{MS}=45 \%, p=$ $0.87)$, selective reporting $(\mathrm{M}=7 \%, \mathrm{MS}=1 \%, p=0.006)$ or other bias ( $M=15 \%, M S=5 \%, p=0.0011)$.

Contrasting MS with S, MS reviews were significantly more likely to come from original studies with low risk of bias judgements in the categories of selective reporting $(\mathrm{MS}=88 \%>\mathrm{S}=54 \%, p<0.001)$. S reviews were more likely to have a greater proportion of low-risk judgements in the domain of allocation concealment $(\mathrm{S}=37 \%>\mathrm{MS}=29 \%, p$ $<0.001)$. Differences between the two interventions were non-significant in random sequence generation $(\mathrm{MS}=36 \%$, $\mathrm{S}=42 \%, p=0.055$ ), blinding of participants and personnel (MS $=19 \%, \mathrm{~S}=21 \%, p=0.038$ ), blinding of outcome assessment (MS $=29 \%, \mathrm{~S}=22 \%, p=0.524$ ), incomplete outcome data (MS $=68 \%, \mathrm{~S}=67 \%, p=0.826)$ and other bias (MS = $52 \%, \mathrm{~S}=51 \%, p=0.721)$. S reviews were more likely to have studies with a high risk of bias in the areas of random sequence generation $(S=12 \%>S=1 \%, p<0.001)$, selective 


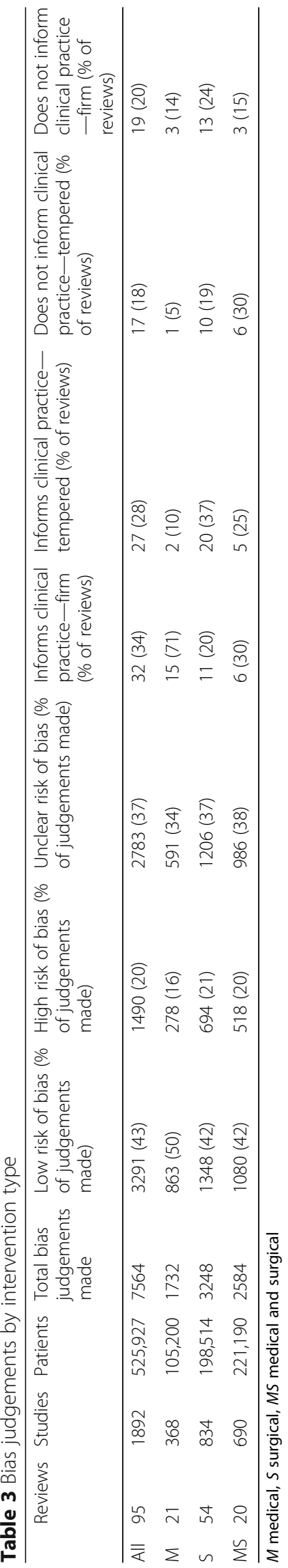




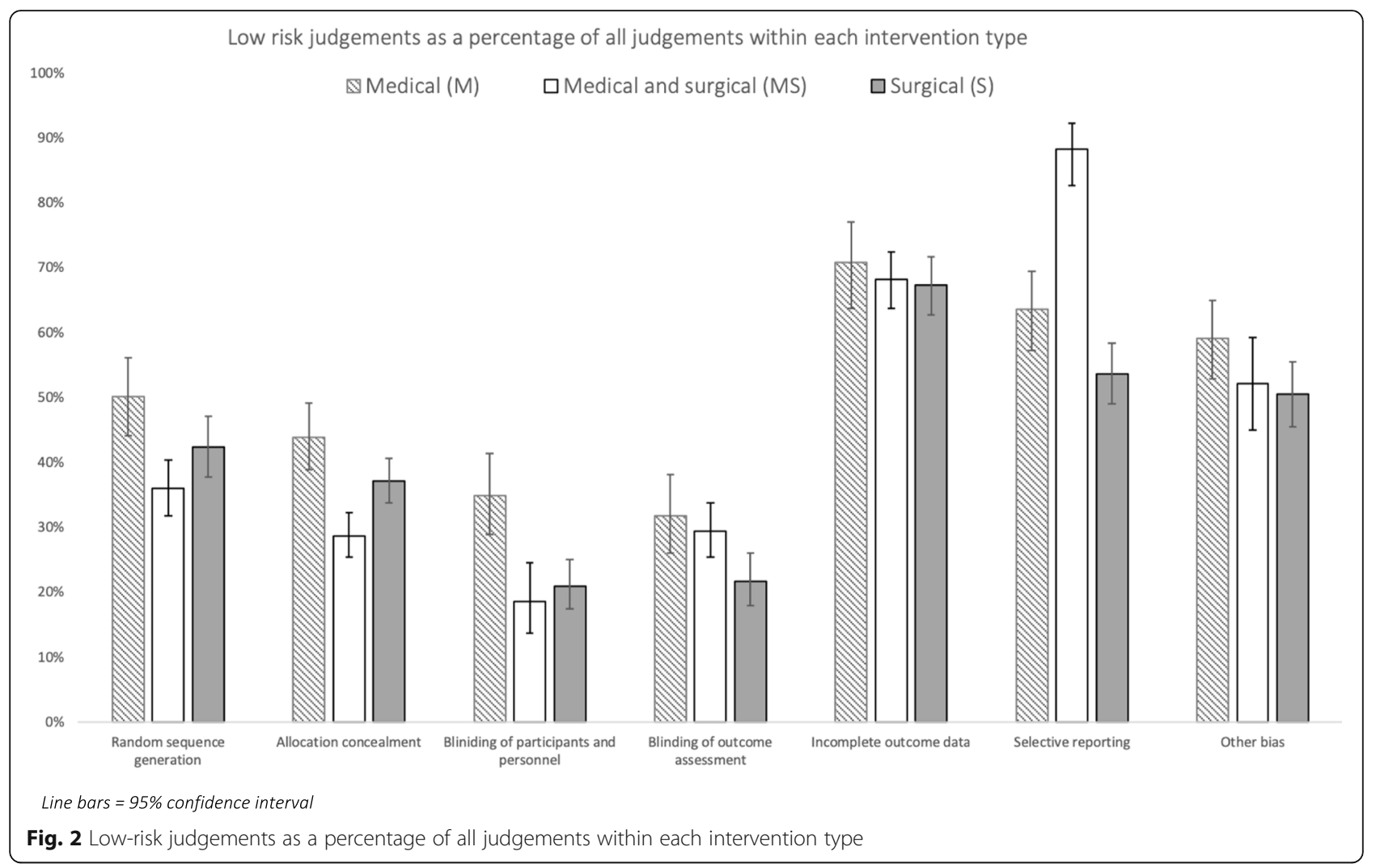

reporting $(\mathrm{S}=13 \%>\mathrm{MS}=1 \%, p=0.001)$, and other bias ( $\mathrm{S}$ $=16 \%>\mathrm{MS}=5 \%, p<0.001)$. MS was more likely to have a high risk of bias judgement in allocation concealment (MS $=20 \%>\mathrm{S}=11 \%, p<0.001$ ) and incomplete outcome data (MS $=27 \%>\mathrm{S}=17 \%, p<0.001)$. No difference was found in blinding of outcome assessment ( $\mathrm{MS}=45 \%, \mathrm{~S}=48 \%, p$ $=0.411$ ).

Overall, the reviews firmly informed clinical practice (I-F) $34 \%$ of the time $(n=32 / 95)$ and informed practice in a tempered fashion (I-T) $28 \%$ of the time $(n=27 / 95)$. A conclusion that did not inform clinical practice but was tempered (N-T) was made $18 \%$ of the time $(n=17 /$ 95) and a conclusion that did not inform clinical fashion and was firm (N-F) was made $20 \%$ of the time $(n=19$ / 95). There was substantial [20] inter-observer agreement on the conclusiveness of the reviews (weighted kappa = 0.622). Initial disagreements were primarily found in the differentiation between firm and tempered conclusions; comparison of "informs clinical practice" vs "does not inform clinical practice" decisions revealed a kappa of 0.753. A consensus was achieved for each review.

A chart of the conclusiveness of reviews by intervention is shown in Fig. 3. There was a significant difference between the groups when assessed using chi-square ( $d f 6$, 20.274, $p=0.002$ ). Comparison of individual groups using chi-square with a Bonferroni correction $(\alpha=0.004)$ was performed. $M$ reviews were significantly more likely to provide conclusion that firmly informed clinical practice than $\mathrm{S}(\mathrm{M}=71 \%>\mathrm{S}=20 \%, p<0.001)$ but not MS $(\mathrm{M}=$ $71 \%, \mathrm{MS}=30 \%, p=0.0294)$. Reviews informed clinical practice (regardless of whether firm or tempered) in $81 \%$ of $\mathrm{M}$ reviews, $55 \%$ of MS reviews and $57 \%$ of $\mathrm{S}$ reviews, but there was no significant difference between these groups ( $\mathrm{M} \vee \mathrm{S} p=0.066, \mathrm{M} \vee \mathrm{MS} p=0.1, \mathrm{~S} \vee \mathrm{MS} p=1$ ).

The risk of bias groups and their relationship to conclusion type were examined via chi-square, with a significant difference found between the groups (chi-square, $d f 6$, $311.465, p<0.001)$. Comparison of I and $\mathrm{N}$ groups using chi-square with a Bonferroni correction $(\alpha=0.0018)$ revealed a significant difference in the likelihood of input studies being judged as having a low risk of bias between them $(\mathrm{I}=46 \%>\mathrm{N}=35 \%, p<0.001)$.

Chi-square with a Bonferroni correction $(\alpha=0.0018)$ was used to examine whether there was any association between the seven risk of bias categories and a review's likelihood to inform clinical practice. Risk of bias domains that had a significant association between low-risk judgements and conclusion type were blinding of outcome assessment $(\mathrm{I}=42 \%$ low risk $>\mathrm{N}=17 \%$ low risk, $p<0.001)$, selective reporting $(\mathrm{I}=72 \%>\mathrm{N}=42 \%, p<$ $0.001)$ and other bias $(\mathrm{I}=59 \%>\mathrm{N}=36 \%, p>0.001)$. There was not a significant association found between random sequence generation ( $\mathrm{I}=42 \%, \mathrm{~N}=41 \%, p=$ $0.939)$, allocation concealment $(\mathrm{I}=37 \%, \mathrm{~N}=30 \%, p=$ 
Conclusiveness of recommendation by intervention type

$₫$ Medical $\square$ Medical \& Surgical $\square$ Surgical
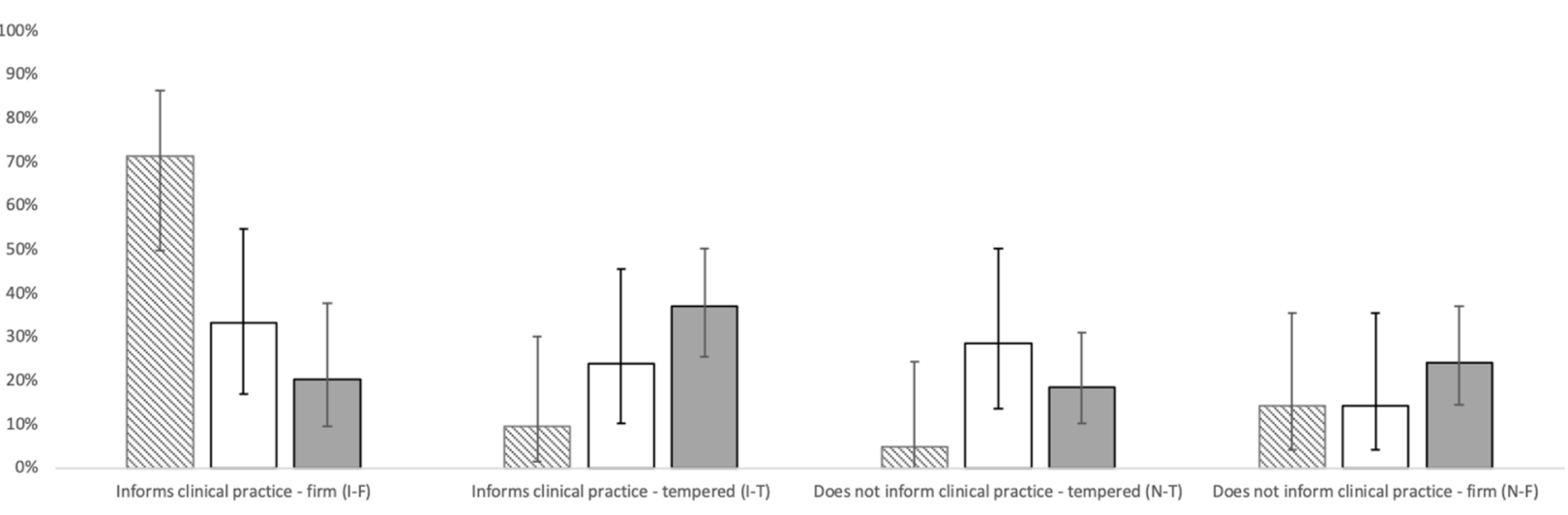

Error bars $=95 \%$ confidence interval

Fig. 3 Conclusiveness of recommendation by intervention type

0.017), blinding of participants and personnel $(\mathrm{I}=27 \%$, $\mathrm{N}=17 \%, p=0.004)$ and incomplete outcome data ( $\mathrm{I}=$ $68 \%, \mathrm{~N}=68 \%, p=0.871$ ). A chart of risk of bias by ability to inform clinical practice is shown in Fig. 4.

For interest, the conclusions of a subgroup of reviews that considered laparoscopic interventions were assessed, shown in Table 4. Seventeen reviews were found. The modal recommendation was I-T in 8 (47\%), followed by N-F in 5 (29\%), N-T in $2(12 \%)$ and I-F in 2 (12\%). A "word cloud" made using descriptions of evidence quality from the conclusions of each of these reviews may be seen in Fig. 5 .

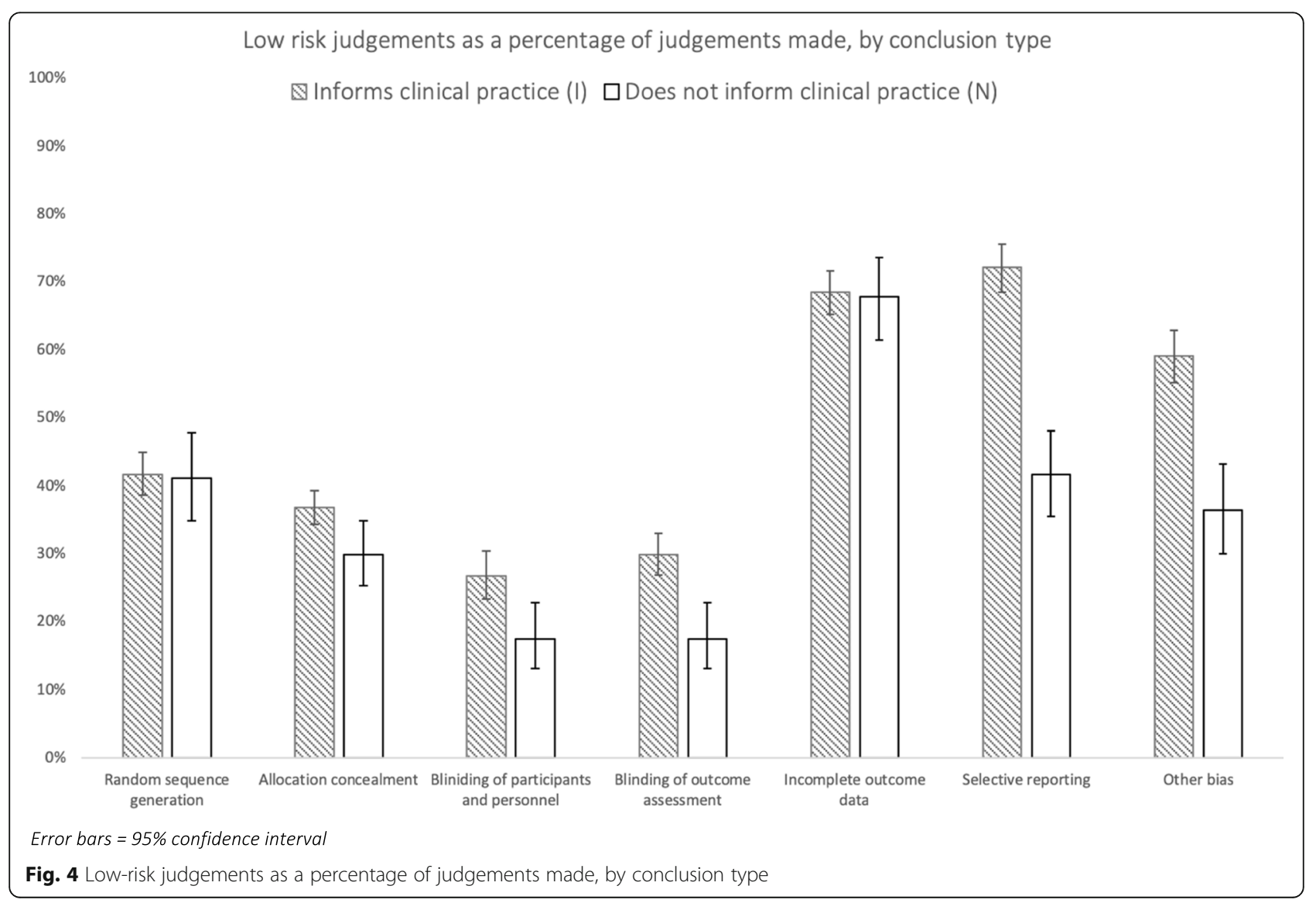




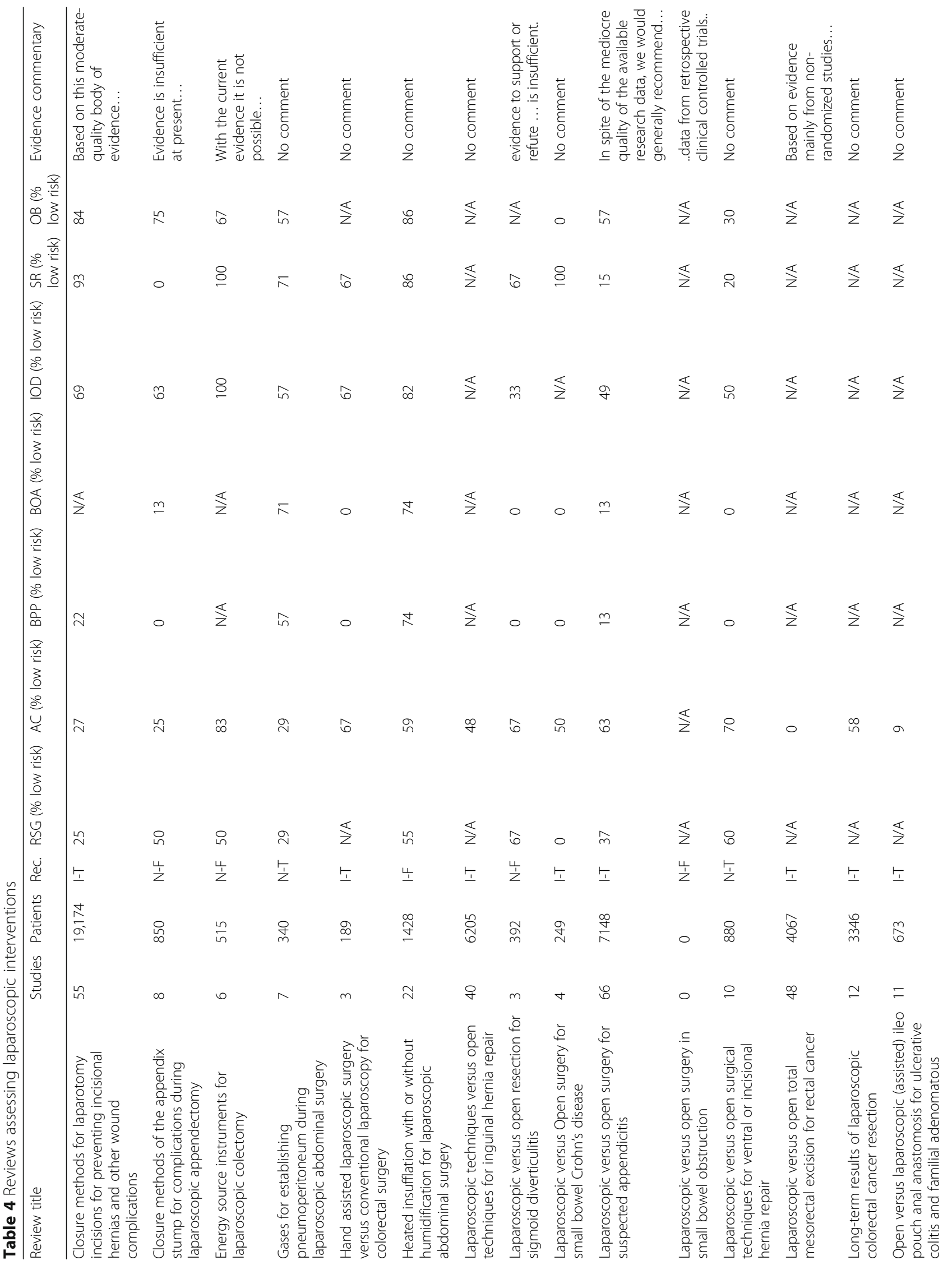




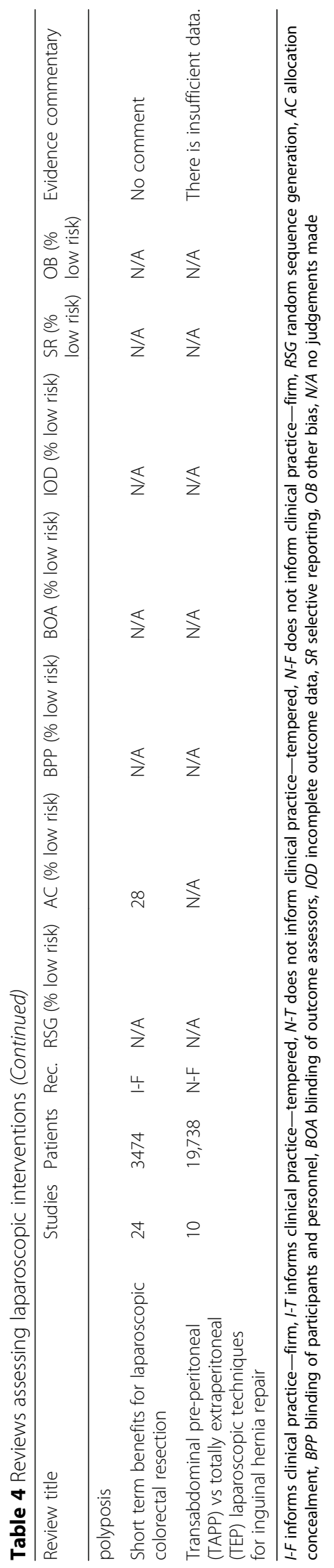




\section{Discussion}

This review has gathered previously made judgements on the risk of bias from a large sample of original research within the colorectal field and combined them, forming a portrait of the risk of bias within the discipline generally. We have then added to this data new judgements regarding the type of intervention studied and the clinical relevance of the meta-evidence produced. Using this approach, a view of the quality of data input and data output within colorectal science may be formed. The importance of these results relates to the defining characteristic of intervention-based medical research: the drive to improve patient outcomes. Studies that exhibit a high risk of bias lead to meta-evidence that is less able to guide clinical outcomes, together forming clinical "noise", from which clinicians are tasked with separating the "signal". The results of this review illustrate the benchmarks within colorectal science of "signal" and "noise", and whether there are any associated factors that will help guide the production of useful original and combined evidence.

When the Cochrane Colorectal Cancer Group examines the risk of bias in original studies within colorectal science, it found the risk of bias to be low in the minority of cases. Notably, many of the studies assessed by the CCCG do not specifically address questions surrounding colorectal cancer per se (for instance, "Cisapride for Intestinal Constipation" [21], or "Antibiotics for uncomplicated diverticulitis" [22]), but rather provide an overview of colorectal science in general, with an inclination towards cancer research. The opinion of the Cochrane group was that the risk of bias within this sample was high or unclear in greater than half of cases. If we consider risk of bias judgements that could possibly have been made but were not to be "unclear" the proportion of low-risk judgements to high or unclear drops further. This review suggests that the minority rate of low-risk judgements across all of the CCCG should be noted by researchers and readers in the colorectal discipline. Efforts to

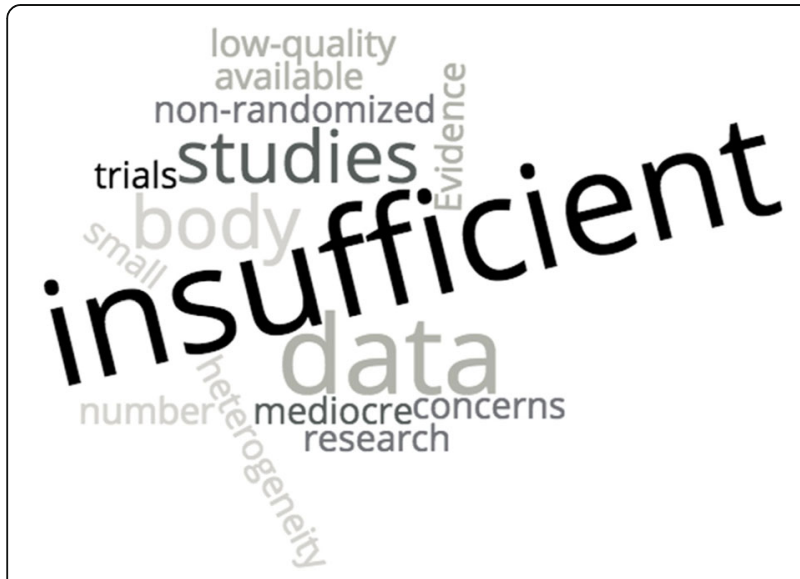

Fig. 5 Word cloud of commentary on evidence within laparoscopic review conclusions minimize the risk of bias within this field should be considered, led by feedback from meta-evidence.

There was an association found between the intervention type and the level of low risk of bias judgements made. Studies concerning a medical intervention (M) were significantly more likely to display low risk of bias than studies concerning a surgical intervention only, or studies with a surgical and medical intervention. Studies that assessed only a surgical intervention were judged to have a low risk of bias at a rate that was not significantly different to studies that assessed a medical and surgical intervention. S reviews and MS reviews were significantly more likely than $\mathrm{M}$ reviews to have high-risk judgements. This may suggest that the addition of a surgical intervention may decrease the amount of bias protection inherent in the assessment of a medical intervention.

Across all interventions, the rate of low-risk judgements was $50 \%$ or less in random sequence allocation, allocation concealment and blinding of outcome assessment and participants and personnel. That the randomization, concealment and blinding for all studies within the CCCG reviews were judged as having high or unclear risk of bias in more than half of cases is cause for reflection. Previous research has demonstrated that high-risk judgements from the Cochrane risk of bias tool are associated with increased effect sizes $[6,23]$. It should be noted that within this sample over 5000 risk of bias judgements that could have been made were not, which potentially dilutes the generalizability and impact of this finding.

Despite a significant difference in low risk of bias findings between $M$ and $S$ overall, analysis of each domain did not reveal a deeper pattern, though a significant difference was found in the blinding of participants and personnel, and a near-significant difference seen in the blinding of outcome assessors. Perhaps surprisingly, the rate of high-risk judgements made regarding blinding was not significantly different between $M$ and $S$ reviews. Both $M$ and $S$ reviews were judged to be high risk for binding in nearly half of all cases. Difficulty in adequately blinding is the nature of the surgical intervention and remains a systemic challenge to rigorous science in surgery. However, the result for the $M$ group suggests that where practical, medical colorectal studies may benefit from paying particular attention to the risk of bias due to inadequate blinding.

$M$ and MS groups were significantly different across a range of bias categories, with $M$ being more likely than MS to have a low risk of bias in random sequence allocation, allocation concealment and blinding of participants and personnel, and MS being more likely to display low risk in selective reporting. As discussed, the inclusion of a surgical intervention in a study makes participant and personnel blinding 
difficult, which may explain why MS reviews were less likely than $M$ to have a low risk of bias in this domain. Errors in reporting may explain the difference in random sequence generation, as MS was no more likely to be judged as high risk in this area, suggesting the discrepancy to be related to a large proportion of "unclear" judgements. Within allocation concealment, however, MS reviews were more likely to have less low-risk judgements and they were significantly more likely to have a high-risk judgement. The increased exposure to bias from poor allocation concealment within MS reviews is also present when contrasting MS with $\mathrm{S}$ reviews. This result is attributable to the impact of a single MS review, "Antimicrobial prophylaxis for colorectal surgery" [24], which had a high-risk judgement rate for allocation concealment of $45 \%$ and provided 115 of the 133 allocation concealment judgements made.

Intervention type was not associated with whether or not a review would be able to inform clinical practice. The likelihood that a review will make a conclusion that informs clinical practice is similar between surgical, medical and combined medical and surgical meta-evidence, despite the fact that studies that incorporate a surgical intervention are more likely to display high or unclear bias. In contrast, there was an association between whether a review informed clinical practice and the risk of bias. $M$ reviews were better protected against bias than S and MS reviews but were no less likely to inform clinical practice. Where a conclusion did inform practice, the likelihood that it would be firm, rather than tempered, was significantly different $M$ and $S$ reviews, but not M and MS. Reviews that examined a surgical intervention exclusively were less confident about their conclusions but were willing to inform practice. It is speculative, but this may suggest that the threshold for a clinical recommendation within surgical evidence is lower than that in medical evidence. Readers of these reviews should be conscious of the GRADE quality assessments that accompany modern Cochrane reviews [25] and consider all low-quality clinical recommendations cautiously. It may be possible that a new weighting metric for meta-evidence, which combines a weighted risk of bias quality score with the cohort size of each study, may deliver meta-analysis that better accounts for varying input quality.

The subgroup analysis of laparoscopic surgery, including the "word cloud", shows a negative view of the quality of the input studies and a lack of confidence regarding the evidence. In spite of this, a conclusion that informs clinical practice is made in nearly half of all cases, albeit tempered. The following quoted conclusion, regarding the use of laparoscopic or open techniques in the management of suspected appendicitis, one of surgery's most common ailments, illustrates the challenge surgeons face; "In spite of the mediocre quality of the available research data, we would generally recommend to use laparoscopy....in patients with suspected appendicitis unless laparoscopy itself is contraindicated or not feasible" [26].

These findings suggest that the original input studies informing meta-evidence within surgery may be inherently biased in a way that makes evidence synthesis in this field less applicable. In the face of this, evidence-based surgery remains elusive. Novel ways of thinking about surgical research may need to be employed. This is not a new revelation [27], but perhaps there are technological advances now that afford surgical research an opportunity not present before. In particular, cloud-based "big data" collection and machine learning analysis may be useful; an approach where high-fidelity patient and practitioner data are automatically recorded for analysis across multiple centres may provide a better avenue to approximate the real-world impact of surgical interventions.

\section{Strengths and limitations}

The strengths of this "review of reviews" are the large number of Cochrane reviews included in our assessment and the dual independent extraction of data. Cochrane is viewed as the gold standard of systematic reviews. Assessment of risk of bias is standardized across Cochrane trials, which enables comparison. Our methods and definitions have been clearly outlined.

The limitations of this study include the restriction of data to Cochrane reviews only, introducing the possibility of selection bias. The CCCG did not record a judgement in over 5000 of the instances where it could have, creating potential bias. The risk of bias judgements recorded by Cochrane are subjective and open to bias. Likewise, the judgements made by the authors of this review regarding the conclusiveness of each of the Cochrane reviews are subjective.

\section{Conclusion}

The findings of this study highlight a need for more detailed reporting and a greater degree of methodological rigor within original colorectal research. Although the type of intervention was associated with a higher risk of bias, it was not associated with the likelihood of a review to inform clinical practice. Surgical studies, in particular, are prone to a higher degree of bias risk and must be interpreted with caution; a review that included a surgical intervention was likely to have a higher risk of bias but was just as likely to inform clinical practice. This may be reflective of the systemic challenges of surgical research. 


\section{Appendix}

Table 5 Excluded reviews

\begin{tabular}{|c|c|c|}
\hline Review & Year & Reason for exclusion \\
\hline Blood CEA levels for detecting recurrent colorectal cancer & 2015 & Non-interventional \\
\hline Chinese medical herbs for chemotherapy side effects in colorectal cancer patients & 2005 & Herbal \\
\hline Chromoscopy versus conventional endoscopy for the detection of polyps in the colon and rectum & 2016 & Non-interventional \\
\hline Concomitant hyperthermia and radiation therapy for treating locally advanced rectal cancer & 2009 & Radiotherapy \\
\hline Dietary calcium supplementation for preventing colorectal cancer and adenomatous polyps & 2008 & Dietary \\
\hline Dietary fiber for the prevention of recurrent colorectal adenomas and carcinomas & 2017 & Dietary \\
\hline Dietary flavonoid for preventing colorectal neoplasms & 2012 & Dietary \\
\hline Flexible sigmoidoscopy versus fecal occult blood testing for colorectal cancer screening in asymptomatic individuals & 2013 & Non-interventional \\
\hline Follow-up strategies for patients treated for non-metastatic colorectal cancer & 2007 & Non-interventional \\
\hline Herbal medicines for advanced colorectal cancer & 2012 & Herbal \\
\hline Narrow band imaging versus conventional white light colonoscopy for the detection of colorectal polyps & 2012 & Non-interventional \\
\hline Oral traditional Chinese medication for adhesive small bowel obstruction & 2012 & Herbal \\
\hline Perioperative blood transfusions and recurrence of colorectal cancer & 2012 & Blood transfusion \\
\hline Pre-operative radiotherapy and curative surgery for the management of localized rectal carcinoma & 2007 & Radiotherapy \\
\hline Preoperative chemoradiation versus radiation alone for stage II and III resectable rectal cancer & 2013 & Radiotherapy \\
\hline Radiofrequency ablation in the treatment of liver metastases from colorectal cancer & 2012 & Radiotherapy \\
\hline Screening for colorectal cancer using the fecal occult blood test, Hemoccult & 2007 & Non-interventional \\
\hline Selective internal radiation therapy for liver metastases from colorectal cancer & 2009 & Radiotherapy \\
\hline Virtual reality simulation training for health professions trainees in gastrointestinal endoscopy & 2012 & Non-interventional \\
\hline Workload and surgeon's specialty for outcome after colorectal cancer surgery & 2012 & Non-interventional \\
\hline Traditional Chinese Medicine herbs for stopping bleeding from hemorrhoids & 2010 & Herbal \\
\hline Transparent cap colonoscopy versus standard colonoscopy to improve caecal intubation & 2012 & Non-interventional \\
\hline
\end{tabular}

Table 6 Included reviews

\begin{tabular}{|c|c|c|c|c|}
\hline Review & Year & Author & Intervention & Conclusion \\
\hline $\begin{array}{l}\text { Abdominal drainage to prevent intra-peritoneal abscess after open appendectomy for com- } \\
\text { plicated appendicitis }\end{array}$ & 2015 & Nelson RL, et al. & Surgical & $\mathrm{N}-\mathrm{F}$ \\
\hline Adjuvant chemotherapy for small intestine adenocarcinoma & 2007 & Singhal N, Singhal D & Medical & $\mathrm{N}-\mathrm{F}$ \\
\hline Adjuvant Therapy for completely resected Stage II Colon Cancer & 2008 & Figueredo A, et al. & $\begin{array}{l}\text { Medical \& } \\
\text { Surgical }\end{array}$ & I-T \\
\hline Analgesia in patients with acute abdominal pain & 2011 & Manterola C, et al. & Medical & I-F \\
\hline Anti-angiogenic therapies for metastatic colorectal cancer & 2009 & Wagner ADADW, et al. & Medical & I-F \\
\hline Antibiotic prophylaxis for hernia repair. & 2012 & $\begin{array}{l}\text { Sanchez-Manuel FJ, et } \\
\text { al. }\end{array}$ & $\begin{array}{l}\text { Medical \& } \\
\text { Surgical }\end{array}$ & $\mathrm{N}-\mathrm{T}$ \\
\hline Antibiotic regimens for secondary peritonitis of gastrointestinal origin in adults & 2005 & Wong PF, et al. & Medical & I-F \\
\hline Antibiotics for uncomplicated diverticulitis & 2012 & $\begin{array}{l}\text { Shabanzadeh DM, } \\
\text { Wille-Jørgensen P }\end{array}$ & Medical & $\mathrm{N}-\mathrm{T}$ \\
\hline Antibiotics versus placebo for prevention of postoperative infection after appendicectomy. & 2005 & BR Andersen, et al. & $\begin{array}{l}\text { Medical \& } \\
\text { Surgical }\end{array}$ & I-F \\
\hline Antimicrobial prophylaxis for colorectal surgery & 2014 & Nelson RL, et al. & $\begin{array}{l}\text { Medical \& } \\
\text { Surgical }\end{array}$ & I-F \\
\hline Appendectomy versus antibiotic treatment for acute appendicitis & 2011 & Wilms IMHA, et al. & $\begin{array}{l}\text { Medical \& } \\
\text { Surgical }\end{array}$ & I-T \\
\hline Cesarean delivery for the prevention of anal incontinence & 2010 & Nelson RL, et al. & Surgical & I-F \\
\hline
\end{tabular}


Table 6 Included reviews (Continued)

Review
Chewing gum for postoperative recovery of gastrointestinal function
Closure methods for laparotomy incisions for preventing incisional hernias and other
wound complications

Closure methods of the appendix stump for complications during laparoscopic appendectomy

Colorectal stents for the management of malignant colonic obstructions

Combination chemotherapy versus single-agent chemotherapy during preoperative chemoradiation for resectable rectal cancer

Conventional versus LigaSure hemorrhoidectomy for patients with symptomatic Hemorrhoids

Covering ileo- or colostomy in anterior resection for rectal carcinoma

Curative surgery for obstruction from primary left colorectal carcinoma- Primary or staged resection?

Daikenchuto for reducing postoperative ileus in patients undergoing elective abdominal surgery

Duration of adjuvant chemotherapy for patients with non-metastatic colorectal cancer

Early enteral nutrition within $24 \mathrm{~h}$ of colorectal surgery versus later commencement of feeding for postoperative complications

Early versus delayed appendicectomy for appendiceal phlegmon or abscess

Energy source instruments for laparoscopic colectomy

Epidermal growth factor receptor (EGFR) inhibitors for metastatic colorectal cancer

Epidural local anesthetics versus opioid-based analgesic regimens for postoperative gastrointestinal paralysis, vomiting and pain after abdominal surgery

Fast track surgery versus conventional recovery strategies for colorectal surgery

Fluoropyrimidine-HAl (hepatic arterial infusion) versus systemic chemotherapy (SCT) for unresectable liver metastases from colorectal cancer

Gases for establishing pneumoperitoneum during laparoscopic abdominal surgery

Hand assisted laparoscopic surgery versus conventional laparoscopy for colorectal surgery

Heated insufflation with or without humidification for laparoscopic abdominal surgery

Heparins and mechanical methods for thromboprophylaxis in colorectal surgery

Hepatic artery adjuvant chemotherapy for patients having resection or ablation of colorectal cancer metastatic to the liver

Histamine type 2 receptor antagonists as adjuvant treatment for resected colorectal cancer lleostomy or colostomy for temporary decompression of colorectal anastomosis

Incision and drainage of perianal abscess with or without treatment of anal fistula

Interventions for anal canal intraepithelial neoplasia

Intra-abdominal drains for the prophylaxis of anastomotic leak in elective colorectal surgery

Intra-peritoneal prophylactic agents for preventing adhesions and adhesive intestinal obstruction after non-gynecological abdominal surgery

Irinotecan chemotherapy combined with fluoropyrimidines versus irinotecan alone for overall survival and progression-free survival in patients with advanced and/or metastatic colorectal cancer

Lactulose versus Polyethylene Glycol for Chronic Constipation

Laparoscopic techniques versus open techniques for inguinal hernia repair

\begin{tabular}{|c|c|c|c|}
\hline Year & Author & Intervention & Conclusion \\
\hline 2015 & Short V, et al. & Surgical & $N-T$ \\
\hline 2009 & $\begin{array}{l}\text { Aboumarzouk OM, et } \\
\text { al. }\end{array}$ & Medical & I-F \\
\hline 2017 & Patel SV, et al. & Surgical & I-T \\
\hline 2017 & Mannu GS, et al. & Surgical & $N-F$ \\
\hline 2011 & Sagar J & Surgical & I-T \\
\hline 2015 & Resende HM, et al. & $\begin{array}{l}\text { Medical \& } \\
\text { Surgical }\end{array}$ & $N-F$ \\
\hline 2009 & Nienhuijs SW, et al. & Surgical & I-T \\
\hline 2010 & Montedori A, et al. & Surgical & I-T \\
\hline 2004 & De Salvo GL, et al. & Surgical & $N-F$ \\
\hline 2018 & Hoshino N, et al. & $\begin{array}{l}\text { Medical \& } \\
\text { Surgical }\end{array}$ & $N-F$ \\
\hline 2010 & Des Guetz G, et al. & Medical & I-F \\
\hline 2006 & Andersen HK, et al. & Surgical & $N-T$ \\
\hline 2017 & Cheng $Y$, et al. & Surgical & $N-F$ \\
\hline 2011 & Tou S, et al. & Surgical & $N-F$ \\
\hline 2017 & Chan DLH, et al. & Medical & I-F \\
\hline 2016 & Guay J, et al. & $\begin{array}{l}\text { Medical \& } \\
\text { Surgical }\end{array}$ & I-F \\
\hline 2011 & $\begin{array}{l}\text { Spanjersberg WR, et } \\
\text { al. }\end{array}$ & Surgical & $N-T$ \\
\hline 2009 & Mocellin S, et al. & Medical & I-F \\
\hline 2013 & Cheng $Y$, et al. & Surgical & $N-T$ \\
\hline 2010 & $\begin{array}{l}\text { Spanjersberg WR, et } \\
\text { al. }\end{array}$ & Surgical & I-T \\
\hline 2016 & Birch DW, et al. & Surgical & I-F \\
\hline 2004 & $\begin{array}{l}\text { Wille-Jørgensen P, et } \\
\text { al. }\end{array}$ & $\begin{array}{l}\text { Medical \& } \\
\text { Surgical }\end{array}$ & I-F \\
\hline 2006 & Nelson RL, Freels S & $\begin{array}{l}\text { Medical \& } \\
\text { Surgical }\end{array}$ & $N-T$ \\
\hline 2012 & Deva S, Jameson M & Medical & I-T \\
\hline 2007 & Güenaga KF, et al. & Surgical & $\mathrm{N}-\mathrm{T}$ \\
\hline 2010 & Malik Al, et al. & Surgical & I-F \\
\hline 2012 & Macaya A, et al. & Surgical & $N-F$ \\
\hline 2004 & Rolph R, et al. & Surgical & $N-F$ \\
\hline 2009 & Kumar S, et al. & $\begin{array}{l}\text { Medical \& } \\
\text { Surgical }\end{array}$ & $\mathrm{N}-\mathrm{T}$ \\
\hline 2016 & Wulaningsih W, et al. & Medical & $N-F$ \\
\hline 2010 & $\begin{array}{l}\text { Lee-Robichaud H, et } \\
\text { al. }\end{array}$ & Medical & I-F \\
\hline 2003 & Willaert W, et al. & Surgical & I-T \\
\hline
\end{tabular}


Table 6 Included reviews (Continued)

Review
Laparoscopic versus open resection for sigmoid diverticulitis
Laparoscopic versus open surgery in small bowel obstruction
Laparoscopic versus open surgery for suspected appendicitis
Laparoscopic versus open surgical techniques for ventral or incisional hernia repair
Laparoscopic versus open total mesorectal excision for rectal cancer
Lateral pararectal versus transrectal stoma placement for prevention of parastomal
herniation
Laxatives for the treatment of hemorrhoids.
Long-term results of laparoscopic colorectal cancer resection
Management for intussusception in children
Mechanical bowel preparation for elective colorectal surgery
Mesalamine (5-ASA) for the prevention of recurrent diverticulitis
Mesh fixation with glue versus suture for chronic pain and recurrence in Lichtenstein
inguinal hernioplasty
Nitrous Oxide for Colonoscopy

Nonsteroidal anti-inflammatory drugs (NSAID) and aspirin for preventing colorectal adenomas and carcinomas

Nonsurgical therapy for anal fissure

Non-resection versus resection for an asymptomatic primary tumor in patients with unresectable Stage IV colorectal cancer

Open Mesh versus non-Mesh for groin hernia repair

Open Preperitoneal Techniques versus Lichtenstein Repair for elective Inguinal Hernias Open surgical procedures for incisional hernias

Open versus laparoscopic (assisted) ileo pouch anal anastomosis for ulcerative colitis and familial adenomatous polyposis

Operative procedures for fissure in ano

Oral versus intravenous fluoropyrimidines for colorectal cancer

Oral water soluble contrast for the management of adhesive small bowel obstruction

Palliative chemotherapy for advanced or metastatic colorectal cancer

Phlebotonics for hemorrhoids

Postoperative adjuvant chemotherapy in rectal cancer operated for cure.

Pre and peri-operative erythropoeitin for reducing allogeneic blood transfusions in colorectal cancer surgery.

Pre-operative chemoradiation for non-metastatic locally advanced rectal cancer

Pre-operative Nutrition Support in Patients Undergoing Gastrointestinal Surgery.

Prolonged thromboprophylaxis with Low Molecular Weight heparin for abdominal or pelvic surgery

Prophylactic nasogastric decompression after abdominal surgery

Propofol for sedation during colonoscopy

Prosthetic mesh placement for the prevention of parastomal herniation

Quality of life after rectal resection for cancer, with or without permanent colostomy.

Reconstructive Techniques After Rectal Resection for Rectal Cancer

\begin{tabular}{|c|c|c|c|}
\hline Year & Author & Intervention & Conclusion \\
\hline 2017 & Abraha l, et al. & Surgical & $\mathrm{N}-\mathrm{F}$ \\
\hline 2011 & Dasari BVM, et al. & Surgical & I-T \\
\hline 2010 & Cirocchi R, et al. & Surgical & $N-F$ \\
\hline 2010 & Sauerland S, et al. & Surgical & I-T \\
\hline 2011 & Sauerland S, et al. & Surgical & $N-T$ \\
\hline 2014 & S Vennix, et al. & Surgical & I-T \\
\hline 2013 & Hardt J, et al. & Surgical & $\mathrm{N}-\mathrm{F}$ \\
\hline 2005 & Alonso-Coello P, et al. & Medical & I-F \\
\hline 2008 & E Kuhry, et al. & Surgical & I-T \\
\hline 2017 & Gluckman S, et al. & $\begin{array}{l}\text { Medical \& } \\
\text { Surgical }\end{array}$ & $N-T$ \\
\hline 2011 & Güenaga KF, et al. & Surgical & $\mathrm{N}-\mathrm{T}$ \\
\hline 2017 & Carter F, et al. & Medical & $N-F$ \\
\hline 2017 & Sun $P$, et al. & Surgical & I-T \\
\hline 2011 & $\begin{array}{l}\text { Aboumarzouk OM, et } \\
\text { al. }\end{array}$ & Surgical & I-T \\
\hline 2004 & Asano TK, McLeod RS & Medical & I-F \\
\hline 2012 & Nelson RL, et al. & Medical & I-F \\
\hline 2012 & Cirocchi R, et al. & $\begin{array}{l}\text { Medical \& } \\
\text { Surgical }\end{array}$ & I-T \\
\hline 2001 & Scott N, et al. & Surgical & I-T \\
\hline 2012 & Willaert W, et al. & Surgical & I-F \\
\hline 2008 & D den Hartog, et al. & Surgical & $\mathrm{N}-\mathrm{F}$ \\
\hline 2009 & Ahmed Ali U, et al. & Surgical & I-T \\
\hline 2001 & Nelson RL, et al. & Surgical & I-T \\
\hline 2017 & Chionh F, et al. & Medical & I-F \\
\hline 2007 & Abbas S, et al. & Medical & I-F \\
\hline 2000 & Best $L$, et al. & Medical & I-F \\
\hline 2012 & Perera N, et al. & Medical & I-T \\
\hline 2012 & Petersen $\mathrm{SH}$, et al. & $\begin{array}{l}\text { Medical \& } \\
\text { Surgical }\end{array}$ & I-F \\
\hline 2009 & Devon KM, McLeod RS & $\begin{array}{l}\text { Medical \& } \\
\text { Surgical }\end{array}$ & $\mathrm{N}-\mathrm{F}$ \\
\hline 2012 & McCarthy K, et al. & $\begin{array}{l}\text { Medical \& } \\
\text { Surgical }\end{array}$ & I-T \\
\hline 2012 & Burden S, et al. & Surgical & $N-T$ \\
\hline 2009 & Rasmussen MS, et al. & $\begin{array}{l}\text { Medical \& } \\
\text { Surgical }\end{array}$ & I-F \\
\hline 2007 & Verma R, Nelson RL & Surgical & I-F \\
\hline 2008 & Singh $\mathrm{H}$, et al. & $\begin{array}{l}\text { Medical \& } \\
\text { Surgical }\end{array}$ & I-T \\
\hline 2018 & Jones HG, et al. & Surgical & I-T \\
\hline 2010 & $\begin{array}{l}\text { Pachler J, Wille- } \\
\text { Jørgensen P }\end{array}$ & Surgical & $\mathrm{N}-\mathrm{T}$ \\
\hline 2008 & Brown CJ, et al. & Surgical & I-F \\
\hline
\end{tabular}


Table 6 Included reviews (Continued)

\begin{tabular}{|c|c|c|c|c|}
\hline Review & Year & Author & Intervention & Conclusion \\
\hline $\begin{array}{l}\text { Resection versus no intervention or other surgical interventions for colorectal cancer liver } \\
\text { metastases }\end{array}$ & 2007 & Fedorowicz Z, et al. & $\begin{array}{l}\text { Medical \& } \\
\text { Surgical }\end{array}$ & $\mathrm{N}-\mathrm{T}$ \\
\hline Rubber band ligation versus excisional haemorrhoidectomy for hemorrhoids & 2005 & Shanmugam V, et al. & Surgical & I-T \\
\hline Second-line systemic therapy for metastatic colorectal cancer & 2017 & Mocellin S, et al. & Medical & I-F \\
\hline Short term benefits for laparoscopic colorectal resection & 2005 & Schwenk W, et al. & Surgical & I-F \\
\hline Shouldice technique versus other open techniques for inguinal hernia repair & 2012 & Amato B, et al. & Surgical & I-T \\
\hline $\begin{array}{l}\text { Single incision versus conventional multi-incision appendicectomy for suspected } \\
\text { appendicitis }\end{array}$ & 2011 & Rehman $\mathrm{H}$, et al. & Surgical & $\mathrm{N}-\mathrm{F}$ \\
\hline Single layer versus double layer suture anastomosis of the gastrointestinal tract & 2012 & Sajid MS, et al. & Surgical & I-T \\
\hline Stapled versus conventional surgery for hemorrhoids & 2006 & Lumb KJ, et al. & Surgical & I-F \\
\hline Stapled versus handsewn methods for colorectal anastomosis surgery & 2001 & Matos D, et al. & Surgical & $\mathrm{I}-\mathrm{F}$ \\
\hline Stapled versus handsewn methods for ileocolic anastomoses & 2011 & Choy PYG, et al. & Surgical & I-F \\
\hline Surgical intervention for anorectal fistula & 2010 & Jacob TJ, et al. & Surgical & $\mathrm{N}-\mathrm{T}$ \\
\hline $\begin{array}{l}\text { Systemic prokinetic pharmacologic treatment for postoperative adynamic ileus following } \\
\text { abdominal surgery in adults }\end{array}$ & 2008 & Traut U, et al. & $\begin{array}{l}\text { Medical \& } \\
\text { Surgical }\end{array}$ & $\mathrm{N}-\mathrm{T}$ \\
\hline $\begin{array}{l}\text { Transabdominal pre-peritoneal (TAPP) vs totally extraperitoneal (TEP) laparoscopic tech- } \\
\text { niques for inguinal hernia repair. }\end{array}$ & 2005 & Wake BL, et al. & Surgical & $N-F$ \\
\hline Transverse verses midline incisions for abdominal surgery & 2005 & Brown SR, et al. & Surgical & $\mathrm{N}-\mathrm{T}$ \\
\hline Water infusion versus air insufflation for colonoscopy & 2015 & Hafner S, et al. & Surgical & I-T \\
\hline
\end{tabular}

$I-F$ informs clinical practice-firm, $I-T$ informs clinical practice-tempered, $N-T$ does not inform clinical practice-tempered, $N-F$ does not inform clinical practice-firm

\section{Additional file}

Additional file 1: Prisma 2009 checklist. (DOC 64 kb)

\section{Abbreviations}

CCCG: Cochrane Colorectal Cancer Group; I: Informs clinical practice; IF: Informs clinical practice-firm; I-T: Informs clinical practice-tempered; M: Medical intervention; MS: Medical and surgical intervention; N: Does not inform clinical practice; N-F: Does not inform clinical practice-firm; NT: Does not inform clinical practice-tempered; O: Other intervention; ROB: Risk of bias; S: Surgical intervention

\section{Acknowledgements}

Many thanks to the Cochrane Colorectal Cancer Group for their assistance with this review.

\section{Funding}

None.

\section{Availability of data and materials}

The datasets used and/or analyzed during the current study are available from the corresponding author on reasonable request.

\section{Authors' contributions}

$J D$ and $A E$ are responsible for the study conception and design. JD and RC are responsible for the acquisition of data. JD, RC and $A E$ are responsible for the analysis and interpretation of data. JD, RC and AE are responsible for writing and the critical revision of the manuscript. All authors read and approved the final manuscript

\section{Ethics approval and consent to participate}

Not required.

\section{Consent for publication}

Not applicable.

\section{Competing interests}

The authors declare that they have no competing interests.

\section{Publisher's Note}

Springer Nature remains neutral with regard to jurisdictional claims in published maps and institutional affiliations.

\section{Author details}

${ }^{1}$ Northern Clinical School, Sydney Medical School, University of Sydney, Sydney, Australia. ${ }^{2}$ Royal Prince Alfred Hospital, Sydney, Australia. ${ }^{3}$ Kolling Institute of Medical Research, Sydney, Australia.

Received: 1 November 2018 Accepted: 25 March 2019

Published online: 08 April 2019

\section{References}

1. The Cochrane Collaboration. Our Funders 2017 [Available from: http://www. cochrane.org/about-us/our-partners-and-funders/our-funders.

2. The Cochrane Collaboration. About Us 2017 [Available from: http://www. cochrane.org/about-us.

3. Useem J, Brennan A, LaValley M, Vickery M, Ameli O, Reinen $\mathrm{N}$, et al. Systematic differences between Cochrane and non-Cochrane meta-analyses on the same topic: a matched pair analysis. PLoS One. 2015;10(12): e0144980

4. Higgins JPT, Green S. Cochrane Handbook for systematic reviews of interventions version 5.1.0 [updated march 2011]. Version 5.1.0 ed: The Cochrane Collaboration; 2011.

5. Higgins JPT, Altman DG, Gøtzsche PC, Jüni P, Moher D, Oxman AD, et al. The Cochrane Collaboration's tool for assessing risk of bias in randomised trials. BMJ. 2011;343:d5928.

6. Hartling L, Ospina M, Liang Y, Dryden DM, Hooton N, Krebs Seida J, et al. Risk of bias versus quality assessment of randomised controlled trials: cross sectional study. BMJ. 2009;339:b4012.

7. Zeng X, Zhang Y, Kwong JS, Zhang C, Li S, Sun F, et al. The methodological quality assessment tools for preclinical and clinical studies, systematic review and meta-analysis, and clinical practice guideline: a systematic review. Journal of evidence-based medicine. 2015;8(1):2-10. 
8. The Cochrane Collaboration. Cochrane colorectal Cancer Group 2017 [Available from: https://cc.cochrane.org.

9. Garas G, Ibrahim A, Ashrafian H, Ahmed K, Patel V, Okabayashi K, et al. Evidence-based surgery: barriers, solutions, and the role of evidence synthesis. World J Surg. 2012;36(8):1723-31.

10. Ergina PL, Cook JA, Blazeby JM, Boutron I, Clavien PA, Reeves BC, et al. Challenges in evaluating surgical innovation. Lancet. 2009;374(9695):1097-104.

11. Aly EH. Robotic colorectal surgery: summary of the current evidence. Int J Color Dis. 2014;29(1):1-8.

12. Dixon PR, Grant RC, Urbach DR. The impact of marketing language on patient preference for robot-assisted surgery. Surg Innov. 2015;22(1):15-9.

13. van der Pas MH, Haglind E, Cuesta MA, Furst A, Lacy AM, Hop WC, et al. Laparoscopic versus open surgery for rectal cancer (COLOR II): short-term outcomes of a randomised, phase 3 trial. 2013;1(3):210-8.

14. Chen K, Cao G, Chen B, Wang M, X X X, Cai W, et al. Laparoscopic versus open surgery for rectal cancer: a meta-analysis of classic randomized controlled trials and high-quality nonrandomized studies in the last 5 years. Int J Surg. 2017;39:1-10.

15. Delaney JD, Holbrook JT, Dewar RK, Laws PJ, Engel AF. Frequency of equivocation in surgical meta-evidence: a review of systematic reviews within IBD literature. BMJ Open. 2017;7(12):e018715. https://doi.org/10.1136/ bmjopen-2017.

16. Guay J, Nishimori M, Kopp S. Epidural local anaesthetics versus opioid-based analgesic regimens for postoperative gastrointestinal paralysis, vomiting and pain after abdominal surgery. Cochrane Database Syst Rev. 2016;(7): CD001893.

17. Microsoft Corporation. Microsoft excel for mac. 2011.

18. IBM Corp. IBM SPSS statistics for Macintosh. 24.0 ed 2016

19. Cohen J. Weighted kappa: nominal scale agreement with provision for scaled disagreement or partial credit. Psychol Bull. 1968;70(4):213-20.

20. Landis JR, Koch GG. The measurement of observer agreement for categorical data. Biometrics. 1977;33(1):159-74.

21. Aboumarzouk OM, Agarwal T, Antakia R, Shariff U, Nelson RL. Cisapride for intestinal constipation. Cochrane Database Syst Rev. 1:CD007780.

22. Shabanzadeh DM, Wille-Jorgensen P. Antibiotics for uncomplicated diverticulitis. Cochrane Database Syst Rev. 11:CD009092.

23. Savović J, Weeks L, Sterne JA, Turner L, Altman DG, Moher D, et al. Evaluation of the Cochrane Collaboration's tool for assessing the risk of bias in randomized trials: focus groups, online survey, proposed recommendations and their implementation. Systematic Reviews. 2014;3(1):37.

24. Nelson RL, Glenny AM, Song F. Antimicrobial prophylaxis for colorectal surgery. [Review] [210 refs]. 2009;1(1):Cd001181.

25. Guyatt GH, Oxman AD, Vist GE, Kunz R, Falck-Ytter Y, Alonso-Coello P, et al. GRADE: an emerging consensus on rating quality of evidence and strength of recommendations. BMJ. 2008;336(7650):924-6.

26. Sauerland S, Jaschinski T, Neugebauer EA. Laparoscopic versus open surgery for suspected appendicitis. [Review]. 2010;1 (10):Cd001546.

27. Horton R. Surgical research or comic opera: questions, but few answers. Lancet. 1996;347(9007):984-5.

Ready to submit your research? Choose BMC and benefit from:

- fast, convenient online submission

- thorough peer review by experienced researchers in your field

- rapid publication on acceptance

- support for research data, including large and complex data types

- gold Open Access which fosters wider collaboration and increased citations

- maximum visibility for your research: over $100 \mathrm{M}$ website views per year

At BMC, research is always in progress.

Learn more biomedcentral.com/submissions 